\section{Immunregulation durch Glukokortikoide}

\author{
Glukokortikoide sind aus der modernen Pharmakotherapie vieler \\ Erkrankungen nicht mehr wegzudenken. Eine Schweizer Studie weist \\ jetzt darauf hin, dass diese Substanzklasse dabei das Immunsystem \\ nicht unspezifisch supprimiert, sondern selektiv regulieren kann.
}

E in Team des Instituts für Asthmaund Allergieforschung in Davos untersuchte T-Lymphozyten aus dem peripheren Blut von 50 Asthmapatienten, die inhalativ oder systemisch mit Glukokortikoiden behandelt wurden. Als Kontrolle dienten Blutproben von sieben gesunden Probanden.

In den T-Zellen der mit Glukokortikoiden behandelten Patienten war signifikant mehr spezifische MessengerRNA für FOXP3 nachweisbar als in den Zellen von nicht behandelten Patienten oder Kontrollprobanden. Dieses Phänomen war sowohl bei inhalativer als auch bei systemischer Gabe von Glukokortikoiden nachweisbar. Der erst kürzlich entdeckte Transkriptionsfaktor FOXP3 ist charakteristisch für regulatorische T-Zellen, die in der Lage sind, die Immunantworten anderen Effektorzellen zu unterdrücken, und so das Immunsystem in Richtung Toleranz beeinflussen. Der Anstieg der FOXP3-mRNA war bereits 3 Stunden nach systemischer Applikation signifikant, nach
12 Stunden war sogar eine signifikante Zunahme der Zahl von $\mathrm{CD}^{+}{ }^{+} \mathrm{CD} 25^{+}-$ T-Zellen im Blut feststellbar. Die Forscher konnten weiterhin in vitro zeigen, dass in T-Zell-Kulturen gesunder Probanden nach Zugabe von Dexamethason kurzfristig vermehrt FOXP3-mRNA gebildet wurde.

Fazit: Die Ergebnisse dieser Studie legen nahe, dass die Therapie mit Glukokortikoiden nicht nur immunsuppressive und antientzündliche Effekte hat, sondern auch regulatorische T-Zellen induziert. Damit wären Glukokortikoide in der Lage, das Immunsystem im Sinne einer Toleranzentwicklung zu beeinflussen. af

Karagiannidis C et al. Glucocorticoids upregulate $\mathrm{FOXP}_{3}$ expression and regulatory $T$ cells in asthma. J Allergy Clin Immunol 2004; 114: 1425-33

\title{
Glukokortikoid-Wirkung erst in der Lunge
}

\section{Ciclesonid ist ein neues Glukokortikoid zur Asthmatherapie, das erst durch Esterasen in der Lunge in seine aktive Form Desisobutyryl- Ciclesonid (des-CIC) überführt wird. Deutsche Pneumologen prüften, ob im Oropharynx tatsächlich nur die inaktivierte Form vorliegt.}

E in Forscherteam aus Grosshansdorf bat 18 Asthmatiker in zufälliger Reihenfolge $800 \mu \mathrm{g}$ Ciclesonid und $1000 \mu \mathrm{g}$ Fluticason-Dipropionat mit einer $\mathrm{Hy}-$ drofluoralkan-getriebenen Dosierhilfe zu inhalieren. Sofort sowie $15,30,45$ und 60 Minuten nach der Inhalation wurden der Mund ausgespült und die Konzentrationen von Ciclesonid bzw. des-CIC sowie von Fluticason bestimmt.

In fast allen Proben fanden sich Ciclesonid und Fluticason, wobei die Konzentration nach 30 Minuten deutlich abnahm. des-CIC lag nur in sehr geringer Konzentration vor und erreichte seinen Maximalwert etwa 30 Minuten nach Inhalation. Im Vergleich zu Fluticason fanden sich 50\% weniger Ciclesonid und $90 \%$ weniger des-CIC in der Spülflüssigkeit - berechnet auf der Basis der Molekulargewichte. Der Unterschied ist mit $\mathrm{p}<0,001$ signifikant. Weniger als $20 \%$ des deponierten Ciclesonids wurde im
Oropharynx durch Esterasen metabolisiert und damit aktiviert.

Die geringe Konzentration des aktiven Metaboliten dürfte zu weniger Glukortikoid-typischen lokalen Nebenwirkungen wie Heiserkeit und Candidiasis bei der Ciclesonid-Anwendung führen eine Vermutung, die bereits durch die
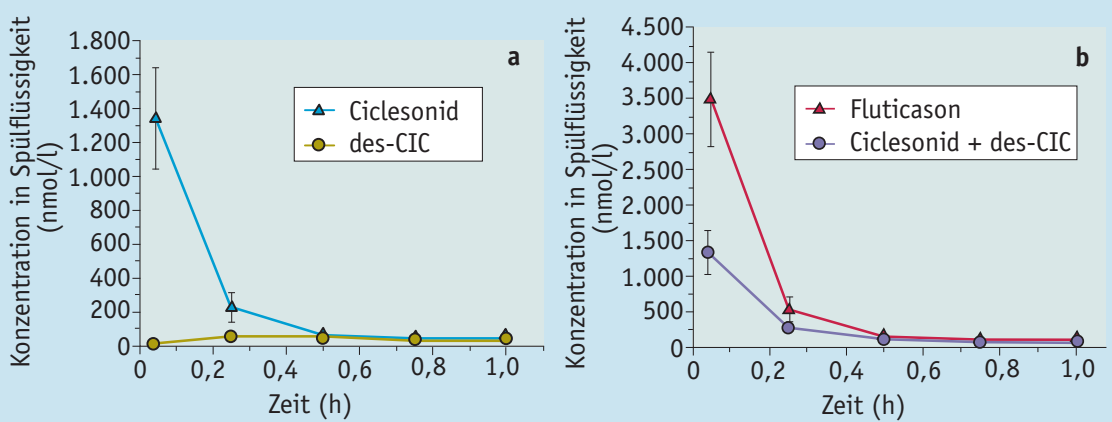

Mittlere Konzentrationen im Mund-Rachen-Raum im zeitlichen Verlauf nach Inhalation von $800 \mu \mathrm{g}$ Ciclesonid und 1.000 Hg Fluticason-Dipropionat; a: Ciclesonid und Desisobutyryl-Ciclesonid (des-CIC); b: Fluticason und Ciclesonid plus des-CIC 